\title{
Espaço social e estrutura de classes em regiões metropolitanas brasileiras
}

Recebido: 20.06.18 Aprovado: 05.10 .18

\section{Emerson Ferreira Rocha*}

Resumo: Esse artigo traz um estudo exploratório sobre a relação entre atitudes e classes sociais no Brasil. Procura-se identificar as classes sociais, definidas com base no exercício de direitos e poderes sobre recursos produtivos, a partir de seu posicionamento no espaço social definido por atitudes referentes ao trabalho, à vida familiar, à vida comunitária, a práticas de consumo cultural, e a posturas políticas. Os dados utilizados são originais, provenientes da pesquisa Radiografia do Brasil contemporâneo, realizada pelo Instituto de Pesquisa Econômica Aplicada (Ipea), durante os anos de 2015 e 2016, com pessoas residentes em regiões metropolitanas brasileiras. Os métodos utilizados partem de Análise de Componentes Principais. Os resultados mostram que três dimensões definem um espaço social de atitudes no Brasil, sendo que a principal se relaciona ao que será chamado de autoconfiança produtiva. A posição das classes sociais ao longo dessa dimensão está intimamente relacionada à posse de recursos produtivos.

Palavras-chave: Desigualdade. Espaço social. Classes sociais. Atitudes. Habitus.

\section{Social space and class structure in Brazilian metropolitan regions}

Abstract: This article presents an exploratory study about the relationship between attitudes and social classes in Brazil. It is sought to identify how social classes, defined on the basis of rights and powers over productive resources, are distributed in a social space defined by attitudes regarding work, family, community, cultural consumption, and politics. The data are from an original qualitative survey conducted by the Institute for Applied Economic Research (Ipea), during the years of 2015 and 2016, with people residing in Brazilian metropolitan regions. The methodology applied in this analysis is based on Principal Component Analysis. The results show that three dimensions define a social space of attitudes in Brazil, and that the main dimension is related to productive self-confidence. The position of social classes across this dimension is closely related to the possession of productive resources.

Keywords: Inequality. Social space. Social classes. Attitudes. Habitus.

\section{Introdução}

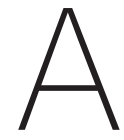

relação entre a posição socioeconômica de pessoas e grupos, por um lado, e suas atitudes, por outro, constitui importante tema de investigação. A partir das definições de classe social baseadas em critérios como posse de ativos, exercício de autoridade e qualificação acadêmica, diferentes pesquisadores

\author{
* Emerso \\ Ferreira Rocha é \\ professor adjunto \\ no Departamento \\ de Sociologia da \\ Universidade de \\ Brasília (UnB), \\ Brasília (DF), Brasil. \\ <erochedo@gmail. \\ com>.
}


têm investigado como esse tipo de constructo pode explicar atitudes e comportamentos prováveis em diferentes esferas de sentido e de ação - especialmente a política -, mas também em outros domínios como o do consumo cultural. Diante dessas ambições teóricas e no contexto de aceleradas transformações no mundo do trabalho e nas relações entre Estado e sociedade, alguns pesquisadores argumentaram pela perda no poder explicativo do conceito de classe (Clark, Lipset \& Rempel, 1993), enquanto outros procuraram afirmar a sua persistência (Hout, Brooks \& Manza, 1993). Outros, ainda, lançaram o argumento de que, para se resguardar a validade do conceito, seria necessário utilizar esquemas de classificação menos abstratos e com menor nível de agregação, com o que as classes sociais, assim definidas, se relacionariam mais de perto com as dinâmicas reais de interação, formação de interesses e de solidariedades na vida social (Grusky \& Sørensen, 1998).

Passando um pouco ao largo da tradição de estudos sobre estratificação social representada por autores como Wright (2009) e Goldthorpe (2004), Bourdieu (1979) propõe uma renovação do debate a partir de uma definição holística de classe. Nessa definição, o próprio conceito de classe conteria em si dimensões diversas como posse de capitais, padrões de consumo, atitudes políticas, além de outras. Ao invés de um conjunto discreto e parcimonioso de eixos de classificação e de regras para combiná-los, o mapeamento das posições de classe deveria ter como base a análise exploratória da variação conjunta desse conjunto amplo de variáveis. Com isso, o conceito de classe tornar-se-ia uma poderosa ferramenta para compreender como as condições de existência das pessoas se relacionam com dinâmicas sociais de grande escala, sobretudo do ponto de vista da reprodução de estruturas de desigualdade. Do ponto de vista analítico, o custo de tal proposta é um conceito de classe excessivamente endógeno, que contém, em sua própria definição, um excesso de informações sobre eventos e práticas que ele pretende explicar.

Este artigo se baliza pelo intuito de mobilizar algumas ideias do argumento de Bourdieu, sobretudo no que concerne à ideia de um espaço de distâncias e de proximidades sociais. Contudo, a proposta procura evitar o referido problema de endogeneidade, estabelecendo-se uma diferença entre as dimensões definidoras da posição de classe, por um lado, e as dimensões definidoras da posição no espaço social, por outro. Trabalha-se, assim, com um conceito de classe mais estritamente socioeconômico e então procura-se mapear a posição dessas classes em um espaço social definido por atitudes referentes ao trabalho, à vida familiar, à vida comunitária, a práticas de consumo cultural e a posturas políticas. A próxima seção apresenta com mais vagar essa orientação teórica. A seção seguinte apresenta a metodologia e os dados. Na sequência, uma seção discute o resultado. Finalmente, a conclusão traz alguns apontamentos gerais. 
Bourdieu (1979) propõe a noção de espaço social a partir de uma crítica aos estudos quantitativos que, partindo de uma definição mais estritamente econômica de classe social, passam a analisar, de um lado, os efeitos da classe sobre desfechos como consumo e atitudes políticas e, de outro, a investigar a posição de classe como efeito de fatores como a escolaridade e a origem social. Tal crítica radica na rejeição das metodologias calcadas na identificação de efeitos parciais, particularmente análises de regressão. No lugar dessas técnicas, o autor advoga por métodos de análise exploratória de dados, fundados na redução dimensional. Enquanto a primeira abordagem tem o intuito de analisar - no sentido estrito de separar - os efeitos mensuráveis de determinado fator, na situação - real ou hipotética - de outros fatores mantidos constantes, as segundas procuram inspecionar a variação conjunta de um "sistema de variáveis" (Bourdieu, 1979: 113), extraindo um número reduzido de dimensões que responde por porções consideráveis daquela variação conjunta. Do ponto de vista substantivo, esse número reduzido de dimensões constituiria um conjunto de eixos definidores de distâncias e de proximidades sociais.

É importante notar que esses eixos, extraídos mediante análise exploratória de um conjunto de variáveis, são definidores do espaço social num sentido heurístico, e não teórico-constitutivo. A definição de um espaço social definido pelo volume global de capitais econômico, cultural e social e pela estrutura de distribuição relativa dos capitais econômico e cultural não constitui um enunciado geral, mas a conclusão de uma análise de dados específica. Embora, em vários momentos, Bourdieu extrapola essa conclusão em um modelo de possível generalização ${ }^{1}$, isto é, feito num nível de teorização de médio alcance. A definição propriamente abstrata e geral do espaço social se refere a um conjunto de "propriedades pertinentes", dentre as quais se diferencia, por princípio, uma "propriedade fundamental", concernente à posição profissional2, de um amplo espectro de "propriedades secundárias" (Bourdieu, 1979: 118). Nesse nível de abstração, as classes sociais são definidas pela "intricada rede de relações" entre as "variáveis pertinentes", sendo forçoso que se considere tanto a variável fundamental como as secundárias (Bourdieu, 1979: 119). É no sentido das diferentes configurações assumidas por essa rede de relações que o autor fala das classes sociais como "classes de condição de existência" (Bourdieu, 1979: 128). A posição de classe deveria, assim, ser determinada simultaneamente pela profissão, renda, escolaridade, idade, extração social, pelo sexo, lugar de moradia e pelas mais diversas práticas de consumo cultural $^{3}$. A metodologia de análise exploratória de dados seria o meio para determinar empiricamente, em cada caso, a configuração da rede de relações entre
1. Ver, por exemplo, a discussão de Bourdieu (1996) sobre espaço social e classes em Razões práticas.

2. O autor fala de "propriedade fundamental", no contexto de uma crítica que se pode presumir endereçada à abordagem neomarxista, donde se pode levantar dúvidas sobre se a disjuntiva entre propriedades fundamentais e secundárias integra a sua própria definição teórica de classes sociais. Contudo, o uso reiterado do termo "propriedades secundárias" ou

"características auxiliares" (Bourdieu, 1979: 113-116), no contexto de suas próprias proposições acerca do que constitui o espaço das classes sociais, mostra que o autor considera, por princípio, a posição profissional como a mais importante das propriedades pertinentes.

3. A rigor, a definição abstrata não especifica, $a$ priori, o conjunto das propriedades que podem ser consideradas pertinentes. 
essas diferentes propriedades pertinentes. As possibilidades de generalização de um resultado específico, como as dimensões extraídas a partir de levantamentos realizados durante a década de 1960, na França, constituem questão aberta à pesquisa empírica. Em outras palavras, a definição mais geral de classes e de espaço social, em Bourdieu, se refere a uma noção não apenas multidimensional, mas holística de classe social, assim como à ideia de espaço social enquanto estado dinâmico, produto do comportamento conjunto dessas múltiplas dimensões no estabelecimento de proximidades e de distâncias sociais.

A perspectiva apresentada neste trabalho faz referência a essa proposta, mas se distancia dela justamente em um aspecto fundamental. Ao invés de se adotar uma noção holística de classe para mapear um espaço social, adota-se uma definição de classe mais estritamente econômica e considera-se, como outro constructo, o espaço social das atitudes. Rejeita-se, portanto, a ideia de que as classes sociais devam ser concebidas como condições de existência no sentido mais abrangente possível, adotando-se, antes, uma definição de classes sociais mais centrada no arranjo de distribuição de direitos e de poderes sobre os recursos produtivos. A capacidade elucidativa da noção de classe ainda está fortemente atrelada às condições gerais de existência de pessoas e de grupos, mas estritamente na medida em que essas condições são afetadas pela posição das pessoas e dos grupos na distribuição daqueles direitos e poderes específicos.

Nessa acepção, a estrutura de classes passa a ser definida em relação à distribuição de recursos intrinsecamente econômicos (ativos de capital), recursos com realização econômica, como qualificações escassas, ou ainda recursos organizacionais, como o exercício de autoridade na ocupação profissional (Goldthorpe, 2004; Wright, 2009). A aquisição, a posse e, em alguns casos, o exercício de controle, por delegação, sobre esses recursos produz, por assimetrias, relações de poder. No nível teórico, a estrutura de classes consiste na configuração global dessas relações de poder. No nível operacional, em estudos empíricos que adotam indivíduos como unidades de análise, ela é representada por um conjunto de grupos discretos, que ocupam posições especificadas com base em indicadores mensuráveis.

Há diferentes propostas de operacionalização desse tipo de conceito de classe no Brasil, quer dirigidas ao estudo de fenômenos como a mobilidade social (Ferreira, 2001; Ribeiro, 2006), quer identificando os efeitos condicionais da discriminação (Santos, 2005a), quer, ainda, direcionando os estudos mais estritamente à validação de esquemas de classificação para o contexto brasileiro (Carvalhaes, 2015; Scalon, 1998). Embora as propostas variem de acordo com os objetivos e métodos de pesquisa adotados - que impõem, por exemplo, a necessidade de esquemas de 
classificação mais ou menos parcimoniosos -, com a qualidade dos dados utilizados e com diferenças de ênfase teórica (mais neoweberiana ou mais neomarxista, por exemplo), os pesquisadores tendem a concordar que o exercício de poder e de direitos sobre recursos produtivos, assim como a natureza das relações de emprego são dimensões fundamentais para identificar posições de classe no Brasil. No presente estudo, utiliza-se o esquema proposto por Santos (2005b). Essa proposta concede centralidade às dimensões analíticas já salientadas, considerando, ao mesmo tempo, divisões mais próprias ao mundo do trabalho brasileiro, especialmente no que referem aos contextos do autoemprego e a situações de extrema despossessão.

Quanto ao espaço social, ele passa a ser definido a partir de um conjunto de escalas, adotado com o objetivo de investigar atitudes referentes ao trabalho, à família, à comunidade, a práticas de lazer e de consumo cultural e, também, com relação à política. As escalas foram construídas no contexto da pesquisa Radiografia do Brasil contemporâneo, realizada pelo Instituto de Pesquisa Econômica Aplicada (Ipea) entre os anos de 2015 e 2016, e toma como referência estudos exploratórios em países com padrões de desenvolvimento econômico e trajetórias histórico-culturais diversas, como Alemanha e Laos. Assim, ao mesmo tempo em que pressupõe um contexto de economia de mercado, especialmente com um mercado de trabalho impessoal constituído, o instrumento está adaptado ao trato com contextos culturais distintos ${ }^{4}$. No nível mais abstrato, o conjunto das 17 escalas utilizadas foi construído num esforço para conjugar a investigação sobre disposições estéticas e posturas políticas, em seus efeitos de distinção social, com a investigação sobre a formação de disposições morais referentes à autoconfiança e ao lócus de controle como princípio de formação de hierarquias sociais (Souza, 2009).

\section{Metodologia e dados}

No Brasil, especialmente, são raras as pesquisas sobre o espaço social das atitudes. Como a definição de estrutura de classes se refere a variáveis mais tangíveis, sua investigação tem sido possível a partir de bases de dados de natureza demográfica. Já a noção de espaço social, embora teoricamente influente sobre cientistas sociais brasileiros, tem tido poucas oportunidades de tratamento operacional a partir de levantamentos empíricos. A pesquisa Radiografia do Brasil contemporâneo, realizada entre os anos de 2015 e 2016 pelo Ipea, oferece possibilidades para uma investigação exploratória sobre esse tema. O levantamento qualitativo em larga escala, compreendendo sete regiões metropolitanas brasileiras ${ }^{5}$, traz, para uma subamostra de 304 indivíduos $^{6}, 17$ escalas de atitudes, construídas para a identificação de estilos de vida em regiões com economias de mercado. As escalas variam de-5 (cinco ne-
4. Ver B. Rehbein (2016).

\section{Regiões}

metropolitanas das cinco macrorregiões brasileiras: Belém (PA), Manaus (AM) Natal (RN), Recife (PE), Salvador (BA), Rio de Janeiro (RJ), São Paulo (SP), Porto Alegre (RS).

6. A amostragem não é probabilística, mas intencional, contemplando pessoas residentes em localidades com índices de desenvolvimento humano variados, com o objetivo de abranger amplo espectro de condições sociais nos contextos metropolitanos brasileiros. A amostra reflete aproximadamente a distribuição da população segundo fatores como região, sexo e raça e conta com uma sobrerrepresentação de pessoas com nível superior de ensino, grupo de especial interesse para a pesquisa e que contaria com poucas observações caso se buscasse refletir, na amostra, sua proporção na população. Os resultados devem ser considerados tendo em conta essas questões de validade externa. Embora embasadas em análise exploratória de dados, todas as generalizações nesse contexto são de natureza eminentemente teórica. 
gativo) a 5 (cinco positivo) e os valores foram atribuídos, a cada entrevistado, por três pesquisadores diferentes, todos com treinamento em nível de pós-graduação em ciências sociais. Tais atribuições foram feitas com base na leitura completa das entrevistas e tiveram sua consistência checada por coeficientes de correlação intraclasse (ICC), que são apresentados na seção de resultados.

Adicionalmente, a pesquisa traz três escalas que indicam a origem social dos indivíduos. A primeira escala diz respeito ao capital econômico (ICC $=0,87$ ) e procura indicar, a partir das narrativas de trajetória de vida, não apenas a renda como também o patrimônio dos responsáveis e demais residentes nos domicílios dos entrevistados durante sua infância. A segunda escala é similar, porém se referindo aos níveis de capital cultural, incluindo escolarização formal (ICC =0,89). Por último, há uma escala referente ao ambiente social na infância, que opera simultaneamente aos níveis de capital econômico e cultural, permeando os círculos de convívio social nos âmbitos da família extensa e da comunidade (ICC =0,81). As escalas variam de 1 (um) a 5 (cinco); o primeiro valor significa acesso muito baixo a recursos materiais e de conhecimento e o valor mais alto, por seu turno, significa amplo acesso a esses mesmos recursos. Computou-se a média aritmética dessas três escalas para produzir um indicador sintético de origem social para cada indivíduo, que também varia de um a cinco, a ser utilizado nesse estudo.

Quanto às classes sociais, um questionário fechado aplicado a cada entrevistado, em conjunto com o protocolo de entrevista, traz informações sobre ocupações e situação de emprego baseadas nos instrumentos do Instituto Brasileiro de Geografia e Estatística (IBGE), permitindo operacionalizar o esquema de classificação proposto e validado por Santos (2005b). O esquema se baseia nos seguintes eixos de classificação:

a. a contratação - ou a não contratação - de mão de obra e a correlata posse e volume de ativos de capital;

b. qualificações escassas;

c. exercício de autoridade;

d. segmentação rural/urbana; e

e. diferenciação entre atividades manuais e não manuais.

A proposta se baseia em uma teoria centrada nos poderes e direitos sobre recursos produtivos como definidores de localizações de classe (Wright, 2005). As três primeiras dimensões mencionadas são diretamente derivadas dessa proposta neomarxista. As duas últimas procuram dar conta da diversificação interna no inflado 
segmento dos autoempregados no Brasil, assim como da precarização que afeta as classes mais populares de maneira geral.

O presente estudo modifica levemente a proposta de Santos (2005 b), ao agregar trabalhadores e empregados qualificados. Os supervisores, que a princípio, fariam parte dessa classe trabalhadora ampliada (Santos, 2005b: 42), foram mantidos como categoria desagregada, dado o comportamento particular que essa classe apresentou no que diz respeito à sua posição no espaço social das atitudes. Presentes em reduzido número na amostra em estudo (cinco casos), os supervisores se aproximam mais das classes médias do que das trabalhadoras, o que pode indicar que esses poucos casos cobrem situações de profissionais com maior poder relativo, por comparação aos supervisores de maneira geral, em termos de qualificações escassas e exercício de autoridade. Inclui-se também uma categoria para os inativos que, a princípio, refere-se estritamente aos trabalhadores excedentes, mas acaba por contemplar situações especialmente precárias e instáveis de atividade laboral. O esquema, assim como a distribuição dos indivíduos pelas classes na amostra são expostas na Tabela 1:

TABELA 1

DISTRIBUIÇÃO DAS CLASSES SOCIOECONÔMICAS NA AMOSTRA

\begin{tabular}{|l|c|c|}
\hline \multicolumn{1}{|c|}{ Classes socioeconômicas } & Frequência & Proporção (\%) \\
\hline Conta própria & 5 & 1.6 \\
\hline Conta própria precário & 58 & 19.1 \\
\hline Empregados domésticos & 3 & 1.0 \\
\hline Empregados especialistas & 80 & 26.3 \\
\hline Especialistas autoempregados & 26 & 8.6 \\
\hline Gerentes & 11 & 3.6 \\
\hline Grandes empregadores & 14 & 4.6 \\
\hline Inativos & 14 & 4.6 \\
\hline Pequenos empregadores & 17 & 5.6 \\
\hline Supervisores & 5 & 1.6 \\
\hline Trabalhadores & 54 & 17.8 \\
\hline Trabalhadores elementares & 17 & 5.6 \\
\hline Total & 304 & 100.0 \\
\hline
\end{tabular}

Fonte: Radiografia do Brasil contemporâneo, Ipea, 2016. Elaboração própria.

A análise dos dados é realizada em duas etapas. A primeira consiste em inspecionar as 17 escalas de atitude, no objetivo de identificar se sua distribuição conjunta aponta para a existência de um certo número de dimensões que mapeiem um espaço social das atitudes. Ao eleger o tratamento das escalas em nível de mensuração de intervalo, as pontuações dos entrevistados foram submetidas a um estudo explo- 
ratório simples, mediante Análise de Componentes Principais (PCA). Basicamente, a técnica transpõe a variação conjunta das escalas para uma base de dimensões ortogonais, ou seja, independentes entre si. Essas dimensões ortogonais respondem por proporções distintas da variação das escalas. Essa proporção significa, basicamente, o quanto as escalas de atitude se distribuem naquela direção. Quanto maior essa proporção, mais importante é a dimensão, a princípio.

É importante dizer "a princípio" porque, em aplicações como essa, o significado das dimensões deve ser apreciado por seus méritos interpretativos, acessados por sua correlação com as escalas de atitude originais. Basicamente: aquilo que uma dimensão representa depende de quais atitudes estão mais associadas a ela. Como será visto na próxima seção, os resultados mostram três dimensões principais que, respondendo por $55 \%$ da variação total, parecem constituir eixos definidores de um espaço social em termos de autoconfiança produtiva, estilos de vida e enquadramento competitivo.

A segunda etapa da análise tem como objetivo articular o plano das classes sociais ou das atitudes. O caminho escolhido para isso foi o de posicionar as classes socioeconômicas no espaço social. Extraídas as três dimensões principais de interesse substantivo, cada indivíduo na amostra tem uma pontuação nessas dimensões. A pontuação média dos indivíduos de determinada classe socioeconômica pode então ser considerada a coordenada que localiza aquela classe socioeconômica na respectiva dimensão. Com essas coordenadas, é possível construir mapas bidimensionais que dispõem as classes no espaço social. Como são três as dimensões consideradas, são construídos três mapas, dispondo todas as suas combinações, par a par. As classes dos trabalhadores por conta própria, dos empregados domésticos e dos supervisores devem ser consideradas com especial cautela, dado o baixo número de casos com que contam na amostra. No entanto, mantêm-se essas classes desagregadas posto que sua disposição no espaço social parece consistente do ponto de vista interpretativo.

Finalmente, a questão da origem social será incluída na análise de maneira semeIhante. Computou-se a média das pontuações nessa escala para todos os indivíduos de cada classe. Essas médias variam entre 1,33 (classe dos inativos) e 3,27 (especialistas autoempregados). Esses valores são considerados em termos de três intervalos. De 0 a 1,99 considera-se uma origem social precária; de 2 a 2,99, origem social mediana; igual ou superior a 3 , origem social próspera. As classes com essas condições típicas de origem são representadas, respectivamente, por esferas de cor: azul escura, azul clara e dourada. As pontuações exatas de cada classe social, assim como do total de 304 indivíduos, são apresentadas no Anexo 1. 


\section{Discussão dos resultados}

\section{As dimensões do espaço social das atitudes}

Antes de considerar como as classes sociais se distribuem no espaço social, é preciso firmar a interpretação das três dimensões retidas para estudo ${ }^{7}$. A Tabela 2 mostra os resultados da Análise de Componentes Principais, atendo-se a essas dimensões. As colunas dispõem a associação entre cada dimensão e as atitudes analisadas. Associações que dão base à interpretação de cada dimensão são destacadas. Na última coluna, mostra-se a medida da consistência de cada item de escala ${ }^{8}$. Note-se que as escalas têm um sentido dicotômico. Os sinais ao lado dos nomes indicam quais polos foram representados por valores negativos e quais foram representados por valores positivos.

TABELA 2

AS TRÊS DIMENSÕES PRINCIPAIS OBTIDAS PELA APLICAÇÃO DE ACP

\begin{tabular}{|c|c|c|c|c|}
\hline Atitude & Dimensão 1 & Dimensão 2 & Dimensão 3 & Consistência \\
\hline Insegurança (-) ou autoconfiança (+) & 0.3627 & 0.0490 & 0.0618 & 0.67 \\
\hline Coletivismo (-) ou individualismo (+) & -0.1101 & 0.0286 & 0.5080 & 0.43 \\
\hline Heteronomia (-) ou autonomia (+) & 0.3466 & 0.0605 & 0.1076 & 0.48 \\
\hline Pessimismo (-) ou otimismo (+) & 0.3168 & 0.0888 & -0.0539 & 0.60 \\
\hline Passividade (-) ou atividade (+) & 0.3644 & 0.0029 & 0.0360 & 0.60 \\
\hline Ascetismo (-) ou hedonismo (+) & -0.0200 & 0.4034 & -0.0115 & 0.61 \\
\hline Idealismo (-) ou pragmatismo (+) & 0.0822 & -0.2497 & 0.1434 & 0.49 \\
\hline Atividade intelectual (-) ou física (+) & -0.2480 & -0.1932 & -0.1303 & 0.74 \\
\hline Experimentalismo (-) ou tradicionalismo (+) & -0.0104 & -0.4582 & -0.0462 & 0.54 \\
\hline Orientação a família (-) ou a si mesmo (+) & -0.0347 & 0.3099 & 0.3807 & 0.68 \\
\hline Insatisfação (-) ou satisfação (+) & 0.3091 & 0.3091 & 0.0691 & 0.79 \\
\hline Orientação a objetivos (-) ou dispersão (+) & -0.3406 & 0.0547 & -0.0925 & 0.70 \\
\hline Indisciplina (-) ou disciplina (+) & 0.3373 & -0.1764 & -0.0059 & 0.68 \\
\hline Fraco (-) ou forte $(+)$ ethos do trabalho & 0.3013 & -0.2555 & -0.1562 & 0.64 \\
\hline Meritocracia (-) ou igualitarismo (+) & 0.0283 & 0.3642 & -0.4740 & 0.80 \\
\hline A favor (-) ou contra (+) intervenção estatal & -0.0271 & 0.0319 & 0.5209 & 0.67 \\
\hline \multirow[t]{2}{*}{ Autoritarismo (-) ou libertarismo (+) } & 0.1245 & 0.4261 & -0.0618 & 0.86 \\
\hline & Valor próprio & Diferença & Proporção (\%) & Cumulativo (\%) \\
\hline Dimensão 1 & 5.24082 & 2.71435 & 30,8 & 30,8 \\
\hline Dimensão 2 & 2.52647 & 0.99768 & 14,9 & 45,7 \\
\hline Dimensão 3 & 1.52879 & 0.36482 & 9,0 & 54,7 \\
\hline Número de observações & & & & 304 \\
\hline
\end{tabular}

Fonte: Radiografia do Brasil contemporâneo, Ipea, 2016. Elaboração própria.
7. A questão sobre quantas componentes extraídas por PCA importa considerar para a análise não está sujeita a uma resposta unívoca. Há uma indicação geral de se considerar todas as dimensões relacionadas a um valor próprio superior a um. Essa convenção, contudo, deve ser avaliada no contexto de cada aplicação específica, considerando os interesses de pesquisa que envolvem a análise exploratória de dados. Na presente aplicação, a quarta e a quinta componentes apresentaram valores próprios de 1,1639 e 1,0354, respectivamente. Contudo, pela inspeção de sua relação com as escalas originais não se observou nelas qualquer valor interpretativo. As correlações das atitudes com a lista completa de 17 dimensões extraídas pela análise consta no Anexo 2.

8. Como já notado, cada entrevistado foi pontuado nas escalas por três pesquisadores diferentes. Uma medida de correlação foi então utilizada para medir a consistência entre essas atribuições. Valores inferiores a 0.60 (destacados em vermelho na Tabela 2), indicam baixa consistência, devendo o respectivo 
item ser considerado com cautela. Nesse estudo, as correlações desses itens com as dimensões principais são eventualmente levadas em conta quando, do ponto de vista interpretativo, se comportam coerentemente com relação a outros itens, mais consistentes.

9. Sobre os efeitos estratégicos objetivos de práticas subjetivamente desinteressadas, ver Bourdieu (1979).
A primeira dimensão se destaca ao responder, sozinha, por quase um terço da variação conjunta de todas as atitudes. Ela identifica o que pode ser chamado de autoconfiança produtiva. Está relacionada às sensações de autoconfiança e de autonomia individual. Note-se que, no instrumento de pesquisa adotado, ethos do trabalho não se refere ao ascetismo vocacional e sim ao papel da experiência laboral na construção da autoestima. Assim, na dimensão da autoconfiança produtiva, a esfera do trabalho constitui um espaço de autorrealização em que se sustenta uma postura ativa e prospectiva com relação à vida (orientação a objetivos). Essa postura ganha sustentação emocional na satisfação com o estado presente e em expectativa otimista com relação ao futuro. A relevância de uma dimensão como essa em sociedades modernas já foi teoricamente discutida por Souza (2009), com base em uma reconstrução do conceito de dignidade. Por sua vez, Rehbein (2016), explorando versões preliminares dos mesmos dados aqui utilizados, encontrou também indícios sobre a relevância de uma dimensão como essa.

A segunda dimensão identifica um experimentalismo expressivo. A forte ênfase na fruição (hedonismo) e os hábitos acentuadamente experimentais de consumo cultural definem uma estilização da vida pautada pela expressão idiossincrática (orientação a si mesmo). A relação negativa com o ethos do trabalho, assim como o idealismo, apontam para a busca da realização pessoal e da satisfação em outras esferas de valor, que relevem atividades "desinteressadas"9 e menos convencionais. A aproximação de valores igualitários e libertários exprime a inclinação humanista do ethos romântico de autorrealização expressiva. Essa dimensão também foi discutida por Souza (2009) e identificada por Rehbein (2016), no mesmo estudo preliminar no contexto dessa pesquisa. Contudo, quanto a esse aspecto, os resultados apresentados aqui sugerem uma diferença sensível de interpretação.

Souza (2009) argumenta que o expressivismo constitui uma dimensão secundária (por relação à dimensão primária da dignidade) de autorrealização das pessoas em sociedades modernas. Em sua construção, a contraface da estilização expressiva da vida constitui, residualmente, uma ausência de expressivismo. Ao adotar essa orientação, Rehbein (2016: 21) entende que essa dimensão opera como patamar hierárquico separando classes médias estabelecidas, familiares a esse tipo de estilização da vida, de outros segmentos sociais intermediários, como a pequena burguesia e os trabalhadores.

Já os resultados apresentados aqui sugerem que a contraface do experimentalismo expressivo não deve ser concebida de maneira residual, configurando antes o que se pode chamar de convencionalismo pragmático. A forte ênfase sobre o ascetismo e o pendor a hábitos mais convencionais de consumo cultural (tradicionalismo) não 
indicam uma simples ausência de expressão e de estilização da vida, mas sim um tipo de estilização específico, que busca expressar os valores da sobriedade, objetividade, dedicação e compromisso (pragmatismo, orientação à família e ethos do trabalho). A orientação potencialmente autoritária e a ênfase na meritocracia coroam um tipo de valoração da agência individual que não vai na direção da autoexpressão idiossincrática, mas, outrossim, reforça o Eu como lócus de controle, ao mesmo tempo em que o ata a projetos de vida convencionais ${ }^{10}$. Essa oposição entre uma estilização da vida idiossincrática e outra mais tradicional não opera, contudo, como fronteira hierárquica. O expressivismo parece ser característico apenas a classes intermediárias, especialmente àquelas sobremaneira assentadas sobre altos níveis de qualificações escassas. No entanto, e é isso que se quer frisar aqui, essa dimensão traça mais uma diferenciação horizontal entre classes médias do que uma fronteira hierárquica as separando de classes mais baixas.

Por fim, a terceira dimensão estabelece uma distinção entre individualismo engajado e individualismo radical. Embora a saliência das atitudes referentes à meritocracia e à intervenção estatal sugira que essa dimensão se refere a orientações ideológicas, esse não é propriamente o caso pois o teor das falas dos entrevistados mostra que é pouco comum, entre eles, a orientação consistente por um quadro programático definido, o que vai ao encontro de resultados obtidos por pesquisas sobre ideologias políticas no Brasil (Ames \& Smith, 2010; Carreirão, 2002; Oliveira \& Turgeon, 2015; Rennó \& Turgeon, 2016). Daí a opção por falar em termos desses diferentes modos de compreender o individual em competição, e não de orientações ideológicas propriamente ditas ${ }^{11}$.

No individualismo engajado, os projetos de vida individual estão assentados nas relações com outros significativos, tendendo a formar projetos conjuntos (orientação à família). Embora o item coletivismo tenha apresentado pouca consistência, ele indica a prevalência de rotinas de trabalho e práticas de lazer e consumo de caráter coletivo. Além disso, o desempenho individual é concebido sob a ótica de um enquadramento estrutural ${ }^{12}$ e se considera o Estado uma instância de mediação das relações de mercado e de criação de redes de proteção social. Já o individualismo radical enfatiza a capacidade de autodeterminação. Não que o envolvimento em laços familiares e comunitários seja negado. É que, embora atravessados por tais laços, os projetos de vida têm como eixo norteador a trajetória individual. O primado da autodeterminação se projeta sobre o mundo como princípio geral, tendendo-se assim a avaliar a extensão das realizações das pessoas pelo critério exclusivo do mérito. O plano factual das ações, em que as redes sociais de apoio (familiares e comunitárias) são sistematicamente mobilizadas, coexiste com o plano ideacional em que o Eu se projeta desembaraçado dessas redes.
10. As pesquisas quantitativas sobre ideologias políticas entre os brasileiros detectam, de maneira geral, baixo nível de consistência ideológica acompanhado da prevalente tendência a um conservadorismo difuso (Oliveira \& Turgeon, 2015).

Essa tendência a posicionamentos mais conservadores que não assumem, contudo, a forma de uma orientação ideológica coesa, pode constituir na verdade uma expressão do convencionalismo pragmático que, como será visto adiante, parece ser predominante na maior parte dos segmentos sociais.

11. As modalidades de individualismo podem tornar determinadas ideologias mais pregnantes ou atraentes, mas não se pode esperar uma relação de um para um. Esses padrões atitudinais podem ter afinidade com diferentes plataformas. As circunstâncias históricas mais amplas e o horizonte de opções oferecidas pela esfera política funcionalmente diferenciada definirão o curso concreto dessas afinidades possíveis. $\mathrm{O}$ individualismo comunitário, por exemplo, pode se afinar tanto com plataformas de orientação social- 
democrática quanto com plataformas autoritárias. Já o individualismo liberal tem afinidade com o liberalismo democrático, mas a rigidez do individualismo econômico torna palatáveis ações repressivas do Estado sobre a sociedade civil.

12. Nessa pesquisa, o igualitarismo não significa a minoração do argumento do mérito individual, mas antes uma modulação específica desse argumento. A definição operacional dessa escala, constante no material de instrução da pesquisa, traz o seguinte: "Todos nós vivemos em uma sociedade em que o valor do mérito individual, através do esforço e do talento, está institucionalizado Portanto, o que tratamos aqui por igualitarismo não é uma concepção totalmente contraposta a argumentos meritocráticos. Na verdade, a meritocracia não é apenas uma fonte de legitimação da desigualdade, mas também um ideal regulador que pode ser mobilizado para condenar vários tipos de iniquidade. No discurso de uma pessoa, a meritocracia pode surgir sempre para justificar o fato de que uns ganham mais do que outros, têm mais prestígio do que
Como se observa, as três dimensões que compõem o espaço social das atitudes, conforme esse pôde ser observado pelos instrumentos de pesquisa adotados, têm status teórico distintos. A primeira relaciona-se diretamente com a economia enquanto esfera de sentido, com o mundo do trabalho e da produção enquanto ambiente de realização da autoconfiança e da dignidade. A segunda refere-se a estilos de vida, dirigindo-se mais diretamente aos hábitos de consumo como meios para a expressão de valores estéticos. A terceira dimensão, por sua vez, tem a ver com a maneira pela qual as pessoas concebem seu engajamento ou desprendimento com relação a redes (familiares, comunitárias e societais) ${ }^{13}$ de apoio, sobretudo no que se refere ao seu despenho na competição econômica, culminando, assim, em formas diferentes de compreender a ideia de mérito individual.

\section{As classes sociais no espaço social das atitudes}

Uma vez identificadas as dimensões que estruturam o espaço social, pode-se investigar a sua relação com a estrutura de classes. Mais especificamente, será averiguada agora a maneira como as classes socioeconômicas se distribuem no espaço social. Como já dito, essas classes são definidas de acordo com o esquema de classificação proposto e validado por Santos (2005b) ${ }^{14}$. Para determinar as posições das classes no espaço social, optou-se pela pontuação média em cada dimensão. Note-se que a PCA opera uma transformação de variáveis. As dimensões extraídas são variáveis criadas a partir da distribuição conjunta das escalas de atitude, de modo que a cada indivíduo na base de dados corresponde um valor em cada componente extraído. Ao calcular a pontuação média dos indivíduos de uma classe em determinada dimensão, obtém-se a coordenada que localiza a respectiva classe no espaço social. O Gráfico 1 mostra a disposição das classes no espaço definido pelas duas primeiras dimensões. Como já exposto na seção de metodologia, as três diferentes cores das esferas indicam a pontuação média das classes na escala de origem social.

No que diz respeito à autoconfiança produtiva, as classes sociais parecem estar posicionadas, hierarquicamente, em função dos ativos de capital, dos recursos organizacionais e das qualificações escassas. No topo aparecem os grandes empregadores, classe que se destaca pela posse de ativos. Em seguida, vêm os especialistas autoempregados, com altos níveis de qualificação e grande autonomia. Logo abaixo, gerentes e supervisores, posições de classe centradas no controle sobre recursos organizacionais. A classe dos pequenos empregadores ocupa, no que diz respeito à autoconfiança produtiva, posição bem próxima e, mais abaixo, colocam-se os trabalhadores por conta própria, que são menos capitalizados. Os empregados especialistas compõem a última classe com pontuação média positiva em autoconfiança produtiva. Sua posição pode estar relacionada ao caráter mais intelectual do 
GRÁFICO 1

ESPAÇO DA AUTOCONFIANÇA PRODUTIVA E DOS ESTILOS DE VIDA

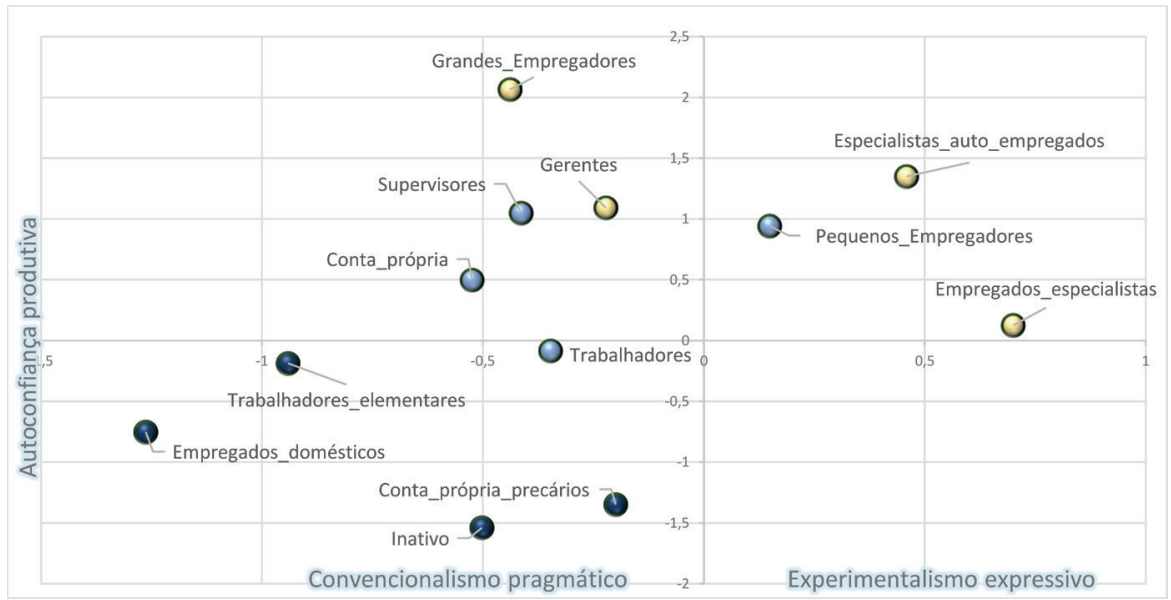

Fonte: Radiografia do Brasil contemporâneo, Ipea, 2016. Elaboração própria.

trabalho que, ao mesmo tempo, sobreleva a autonomia sobre a própria atividade e reduz a tangibilidade da produção e dos resultados, implicando formas mais flexíveis de controle sobre a produção. Essas características fazem desses trabalhadores assalariados uma classe diferente das demais classes trabalhadoras. Ao analisar o espectro negativo da autoconfiança produtiva, vê-se, primeiramente, os trabalhadores, cuja pontuação não chega a ser destacadamente baixa. Por um lado, a vulnerabilidade nas relações de produção tende a reduzir a autoconfiança e, também, a sensação de autonomia individual vinculadas à atividade produtiva. Por outro lado, contudo, o fato de contar com essas proteções atenua a sensação de fragilidade. Mais abaixo, vêm os trabalhadores elementares, cujas atividades incorporam menores qualificações. Em seguida, empregados domésticos. Na base do espaço social, os trabalhadores por conta própria em situação precária e os inativos. Os primeiros são destituídos de capitais e de recursos organizacionais, além de exercerem atividades vinculadas a baixíssimos níveis de qualificação.

A origem social típica em cada classe é consistente com a hierarquia da autoconfiança produtiva e com a distribuição de poderes entre as classes. As classes definidas por maiores ativos de capital, por mais qualificações escassas e por mais recursos organizacionais são aquelas em que é mais comum a origem privilegiada. Observa-se que as classes dos supervisores, dos pequenos empregadores e dos trabalhadores por conta própria são mais permeáveis socialmente, incluindo um maior número de pessoas com origem social intermediária. O mesmo é verdade no que diz respeito aos trabalhadores. Na base, os membros das classes sociais mais destituídas de recursos produtivos e menos autoconfiantes apresentam, geralmente, origem social precária. outros etc. Outra pessoa, contudo, pode mobilizar a ideia de meritocracia mais para criticar as desigualdades existentes: questionar a desigualdade de oportunidades,

de pontos de partida, denunciar discriminações por gênero ou raça, que imprimem desvantagens a despeito do mérito, enfim. $\mathrm{O}$ que chamamos de igualitário comporta essa última vertente do argumento meritocrático, quer dizer, pessoas que mobilizam a meritocracia como argumento de crítica. O que rotulamos de 'meritocracia' corresponde à primeira vertente, mais voltada à legitimação das desigualdades existentes, ou seja, discursos em que a meritocracia surge mais como uma explicação para o atual estado de coisas".

13. Ver, na tabela 2, a associação da terceira dimensão com as escalas de orientação à família, de coletivismo e de apoio à intervenção estatal.

14. A presente aplicação faz duas adaptações da proposta original de Santos (2005b), agregando as categorias trabalhadores e trabalhadores qualificados $e$ incluindo a categoria inativos. 
No que diz respeito aos estilos de vida, nota-se a prevalência do convencionalismo pragmático entre classes sociais com os mais diversos níveis de status socioeconômico. Observa-se uma classe média expressiva, em que se destacam os especialistas autoempregados e os empregados especialistas. Ambas as classes se definem por um alto investimento em capital cultural e por uma atuação profissional que explora esse recurso incorporado com algum grau de dinamismo, enfatizando valores como a criatividade. Quanto aos pequenos empregadores, deve-se observar que, na amostra, essa classe social conta com grande presença de pessoas com formação superior e mesmo com pós-graduação em suas áreas de atuação no mercado, o que pode, em semelhança às classes já mencionadas, favorecer um tipo de estilização da vida mais pautado pela expressão idiossincrática. A classe dos gerentes também é muito marcada pela formação superior e mesmo pela pós-graduação, mas aqui, a ocupação de elevada posição na cadeia de comando de burocracias empresariais mantém mais afinidade com a estilização convencional pragmática, visando à expressão dos valores de sobriedade, comprometimento e objetividade. Esse tipo de estilização da vida também se mostra mais afim a outras classes médias (supervisores e trabalhadores por conta própria) e, também, à classe dos grandes empregadores.

Se é verdade que, entre classes médias e altas, o convencionalismo pragmático performa valores como sobriedade, comprometimento e objetividade, isso não deve ser menos verdade para as classes trabalhadoras e populares. No entanto, situações de classe tão distintas devem ter implicações. Sem a concomitância com o exercício de autoridade no mundo do trabalho, o convencionalismo pragmático pode estar relacionado, entre as classes mais populares, a certo senso de objetividade perante à vida, que se impõe àqueles cuja luta econômica pela existência não pode ser dada por vencida. Por outro lado, o convencionalismo pragmático pode expressar também valores lúdicos e estéticos que não buscam referência a uma esfera de sentido francamente diferenciada.

Com efeito, Max Weber (1982) destaca a ideia de que a esfera estética, enquanto funcionalmente diferenciada, opera com um tipo de argumento transcendente, sob a ótica de um antagonismo com o domínio "mundano", de maneira geral representado como o império das necessidades. As escalas de hedonismo e, especialmente, de experimentalismo utilizadas no instrumento estão fortemente orientadas por essa ideia de experiência estética e, por consequência, o experimentalismo expressivo captado pela redução dimensional. Sugere-se que, com isso, o convencionalismo pragmático capte também valores estéticos que não contam com essa mesma orientação intelectualista mas que, antes, são dirigidos por sensibilidades que valorizam uma "ritualística mundana" (Farias, 2016), pautada não pelo antago- 
nismo entre espírito e necessidade, mas por um tipo de transfiguração do imanente que ocorre quando se soergue a própria satisfação das necessidades ao status existencial de uma celebração. Para esse tipo de sensibilidade, a fruição estética não ocorre para além do reino das necessidades, mas está vinculada a ele. Dada a orientação teórica das escalas utilizadas nessa pesquisa, tal sensibilidade estética ficaria subsumida no convencionalismo pragmático, por oposição ao experimentalismo expressivo, que é intelectualista.

O Gráfico 2 mostra a disposição das classes socioeconômicas no espaço social, considerando a autoconfiança produtiva como eixo vertical e a modalidades de individualismo como eixo horizontal.

\section{GRÁFICO 2}

ESPAÇO DA AUTOCONFIANÇA PRODUTIVA

E DAS MODALIDADES DE INDIVIDUALISMO

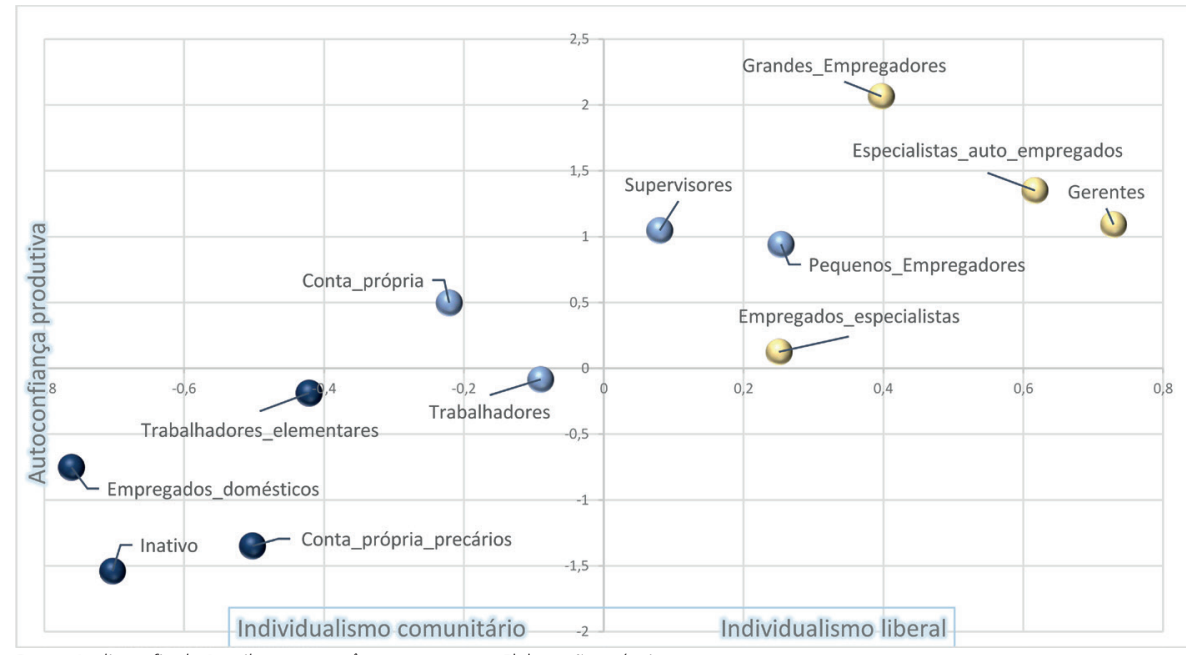

Fonte: Radiografia do Brasil contemporâneo, Ipea, 2016. Elaboração própria.

A distribuição das classes pelo quadrante inferior esquerdo e pelo superior direito mostra um padrão muito nítido. O individualismo liberal é mais comum entre as classes com melhores condições socioeconômicas, em que é maior a autoconfiança produtiva. Já o individualismo comunitário é a marca das classes menos favorecidas ${ }^{15}$. É sintomático que as classes dos gerentes e dos especialistas autoempregados sejam as de mais destacado individualismo liberal. As duas estão calcadas em altos níveis de qualificações escassas e no controle sobre os recursos organizacionais. A situação, em ambas, é marcada não apenas pelo alto investimento em credenciais, como também pelo exercício de funções estritamente dependentes dos conhecimentos práticos e do status profissional vinculados a essas credenciais. Ao ocupar

15. É importante notar que a distribuição das classes nos gráficos não pode ser interpretada em termos de correlação entre as dimensões que definem o espaço social. As dimensões, extraídas por PCA, são, por definição, ortogonais, independentes entre si. O que os gráficos mostram é como as classes se posicionam, simultaneamente, em pares dessas dimensões independentes. 
posições relacionadas a uma trajetória de grandes investimentos materiais, afetivos e cognitivos, em ambientes institucionais altamente competitivos, torna-se forte o sentimento de autorrealização individual, além da tendência, autolegitimadora, de acreditar, sobretudo, na virtude das regras do jogo que venceram. Com isso, o jogo da competição no mundo do trabalho tende a ser visto como depurado de suas contradições e ambiguidades, como encerrando, exclusivamente, um conjunto de mecanismos, transparentes e justos, de distribuição de sanções e de recompensas econômicas.

É notável que esse tipo de individualismo não seja tão radical entre os empregadores. Pode ser que a condição de propriamente capitalista ou de pequeno capitalista imponha uma visão mais realista sobre a natureza das relações de competição no mundo do trabalho. Talvez por estarem à frente da, por assim dizer, realpolitik do mercado, esses indivíduos estejam menos inclinados a acreditar em uma visão desse mesmo mercado que seja por demais depurada de aspectos que, objetivamente, o caracterizam. Claro que gerentes e especialistas também tomam a frente em decisões estratégicas, mas suas trajetórias estão alicerçadas, antes de tudo, em ambientes de competição altamente regulada mediante dispositivos de mensuração explícita de desempenho: da graduação à pós-graduação, daí ao ambiente dos exames e das avaliações no trabalho. Tudo isso favorece uma ideia de desempenho muito mais estritamente vinculada às competências do indivíduo. $\mathrm{O}$ individualismo radical dessas classes teria a ver então com o próprio destaque das competências técnicas na estruturação dessas posições. A posição de classe do capitalista, por sua vez, talvez tenda a deixar mais claro, para o indivíduo, o quanto e como o desempenho econômico efetivo depende, além de competências, também de contingências.

No que diz respeito à origem social, é visível que a crença na autodeterminação radical é mais intensa nas classes com origem social caracteristicamente mais privilegiada, ou seja, justamente entre aqueles que contaram com maior apoio de suas famílias e redes sociais ao longo de suas trajetórias econômicas. Nas entrevistas que compõem a base de dados aqui utilizada, há um padrão narrativo recorrente em entrevistas com pessoas de classes como especialistas autoempregados, gerentes e empregadores. Imediatamente após descreverem o papel crucial exercido, em suas carreiras, pelo acesso a uma rede por onde circulam cuidados e recursos (a herança, um parente colateral que facilitou a entrada em uma empresa ou um sogro que abriu as portas de um influente escritório de advocacia), os entrevistados são capazes de, sem o uso de quaisquer conectores adversativos, afirmarem que os sucessos de suas carreiras são devidos exclusivamente ao seu empenho individual. Isso não ocorre de má fé articulada por parte dessas pessoas, e sim porque as redes de apoio atuam exatamente no sentido de garantir uma 
posição de classe que incute as sensações de autonomia e de autodeterminação radical. Ao concorrerem para carreiras nessas classes sociais e ao investirem na produção de uma narrativa de conquista individual, as famílias e as redes mais extensas de cuidado e suporte criam as próprias condições para o "esquecimento" de seu papel decisivo.

No espectro do individualismo engajado, a classe econômica dos trabalhadores é a que ocupa posição mais moderada. Algo do que se disse sobre especialistas e gerentes pode se aplicar, de maneira muito mais atenuada, aos membros dessa classe. Suas posições estão relacionadas à qualificação técnica, ainda que de nível médio e não superior. Isso fortalece a diligência coordenada entre sistema escolar e mundo do trabalho, da percepção de um forte vínculo entre realizações econômicas e desempenho individual. Por outro lado, o trabalho tende a se concentrar em atividades de rotina realizadas em equipe, fortalecendo, sobretudo, o coletivismo. No caso dos trabalhadores elementares, esta última tendência se intensifica enquanto a primeira arrefece, ditando um padrão mais acentuado de individualismo engajado. Por sua vez, os trabalhadores por conta própria precários, os empregados domésticos e os inativos, por sua situação especialmente frágil quanto à posse de recursos produtivos, tendem a não alimentar um sentido particularmente forte de autodeterminação individual a partir da esfera econômica.

Algo que se depreende de algumas narrativas de membros dessas últimas classes é uma certa tensão entre a fraca sensação de terem capacidade de autodeterminação e, ao mesmo tempo, uma tendência à autorresponsabilização pela situação socioeconômica. Há uma fraca sensação, entre essas pessoas, de que elas poderiam alterar o curso de suas próprias vidas, ao mesmo tempo em que há um sentimento de culpa por não a terem alterado. Esse sentimento de culpa costuma estar vinculado a estigmas sobre a pobreza, como a falta de competência - especialmente intelectual - e a dependência com relação ao Estado, no caso de beneficiários de auxílios sociais ou proteções sociais como pensões. Essa mistura entre os sentimentos de impotência e de culpa assume, por vezes, a forma de uma revolta difusa.

Por fim, os trabalhadores por conta própria encerram um caso especial. Trata-se da única classe econômica que combina autoconfiança produtiva com individualismo engajado. Para eles, a inserção enérgica no mercado como via de emancipação parece ser tal que passa a não incutir fortemente autoconcepções egoicas. Antes, pode-se pensar que, comumente, essa empreitada lança suas condições em redes de apoio mútuo, quer familiares, quer mais ampliadas, que não operam apenas como suporte, mas que são, antes, constitutivas da própria empreitada, como no caso arquetípico do empreendimento familiar. Assim, as conquistas não se projetam 
no plano simbólico de uma realização individualíssima, de uma autodeterminação radical, mas sim no plano de uma trajetória cooperada de vida.

No que diz respeito à origem social, os trabalhadores por conta própria e os trabaIhadores se destacam como únicas classes com origem social tipicamente intermediária que se situam no espectro do individualismo engajado. Além deles, as classes com origem menos favorecida manifestam fortemente esse tipo de individualismo. Diferentemente das condições mais privilegiadas de origem, que permitem simplesmente tomar o engajamento em redes de apoio como pressuposto e projetar sobre o mundo uma representação de si mesmo como um Eu desembaraçado desses laços, as condições de origem mais desfavorecidas explicitam tais laços, quer pela necessidade sistemática de afirmá-los, de fortalecê-los ou de recompô-los, quer pelas ausências que se impõem.

O Gráfico 3 mostra as posições das classes no espaço social definido pelas dimensões do estilo de vida e das modalidades de individualismo.

GRÁFICO 3

ESPAÇO DAS MODALIDADES

DE INDIVIDUALISMO E DOS ESTILOS DE VIDA

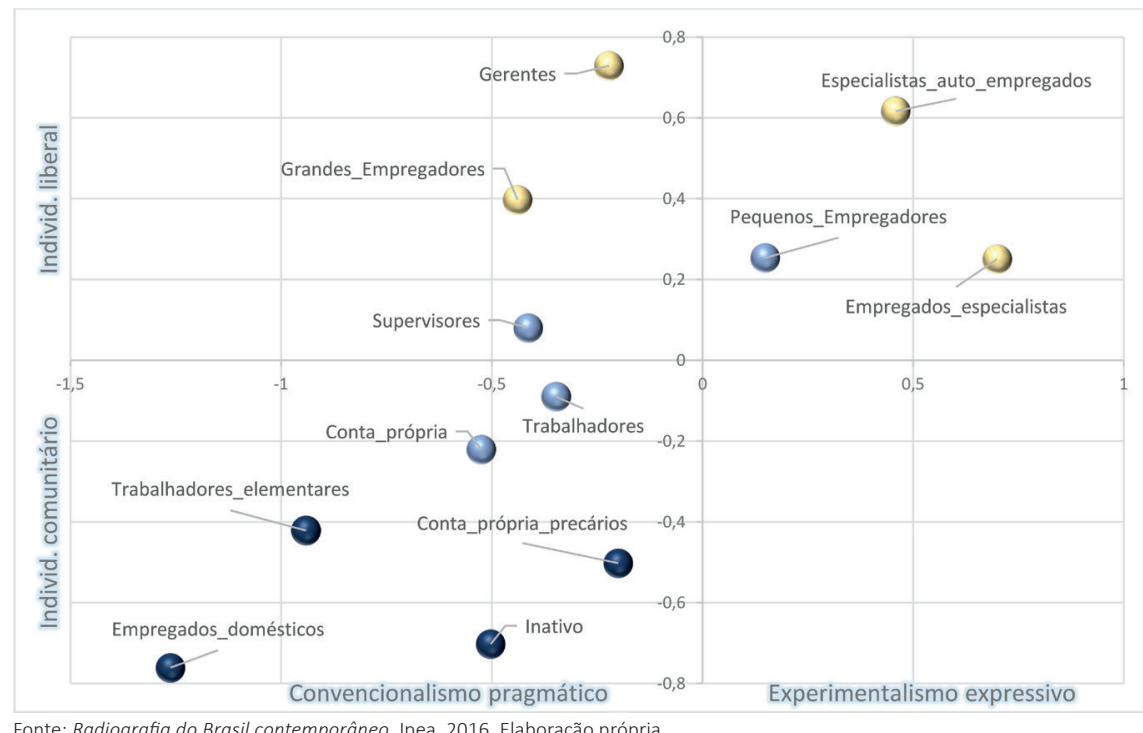

Fonte: Radiografia do Brasil contemporâneo, Ipea, 2016. Elaboração própria.

A rigor, o gráfico não traz informações novas, já que ambas as dimensões já foram abordadas, mas permite melhor visão da sua distribuição conjunta. Fica clara a existência de dois segmentos de classes médias e altas, ambos com uma orienta- 
ção individualista radical, porém distintos em termos de estilos de vida: uma mais expressiva idiossincrática, outra mais convencional pragmática. De outro lado, as classes trabalhadoras e populares tendem, simultaneamente, ao individualismo comunitário e ao convencionalismo pragmático. O experimentalismo expressivo não funciona propriamente como fronteira hierárquica no espaço social, constituindo antes um traço distintivo de classes médias e médias-altas com forte investimento em qualificações escassas. Por sua vez, às classes trabalhadoras e populares, o convencionalismo pragmático parece estar sempre em afinidade com o individualismo engajado, do que se pode depreender uma visão global de mundo especialmente realista. A ideia de um indivíduo plenamente autodeterminado tem menos apelo que a percepção da sua imersão em laços de dependência mútua. O ideal de uma expressão idiossincrática e transcendente atrai menos que o de uma fruição estética que segue o pulso da vida comum e mundana.

\section{Conclusão}

Os resultados desse trabalho confirmam que uma dimensão fundamental, referente à distribuição de autoconfiança produtiva, hierarquiza fortemente a sociedade brasileira. Por outro lado, essa hierarquia parece ter relação discernível com posições de classe definidas em termos de poderes e direitos sobre ativos de capital, de qualificações escassas e de poderes organizacionais (Santos, 2005b), coadunando-se com reflexões mais canônicas sobre classes sociais (Wright, 2009). À estrutura de distribuição de direitos e poderes sobre recursos produtivos, relaciona-se uma estruturação hierárquica da dignidade, compreendida não no sentido normativo, como atributo inerentemente humano, mas no sentido sociológico empírico, como classificação social baseada na distribuição objetiva de capacidades e de atribuições de estima (Souza, 2009). Mais que uma mera repercussão subjetiva da desigualdade entre as classes, a distribuição da autoconfiança produtiva deve ser compreendida como algo a reproduzir essa desigualdade, dado o seu potencial de operar como fator de legitimação e de acomodação. Por outro lado, contudo, embora haja essa reprodução, há também contingência na relação entre o plano das posições de classe e o plano das atitudes. A autoconfiança produtiva encontra-se, ainda que relativamente menos, em segmentos de classes trabalhadoras e populares. Nesse sentido, ela pode operar como disposição para a transformação, como impulso para a inserção produtiva. Há de se lembrar também dos limites na validade externa do levantamento utilizado nesse estudo. Embora se possa assumir que os dados permitem traçar uma imagem verossímil do espaço social de regiões metropolitanas brasileiras, uma amostra estatisticamente representativa e de maior tamanho tenderia a apurar a imagem das classes trabalhadoras e populares, além de permitir exercícios com maiores desagregações, que talvez revelariam segmentos de classes populares com maior autoconfiança produtiva. 


\section{Referências}

AMES, B.; SMITH, A. E. Knowing left from right: ideological identification in Brazil, 2002-2006. Journal of Politics in Latin America, v. 2, n. 3, p. 3-38, Dez. 2010.

BOURDIEU, P. Razões práticas: sobre a teoria da ação. Campinas: Papirus, 1996.

_. La distinction: critique sociale du jugement. Paris: Les Éditions de Minuit, 1979.

CARREIRÃO, Y. DE S. Identificação ideológica e voto para presidente. Opinião Pública, v. 8, n. 1, 2002.

CARVALHAES, F. A. de O. A tipologia ocupacional Erikson-Goldthorpe-Portocarero (EGP): uma avaliação analítica e empírica. Sociedade e Estado, v. 30, n. 3, p. 673-703, Dez. 2015.

CLARK, T. N.; LIPSET, S. M.; REMPEL, M. The declining political significance of social class. International Sociology, v. 8, n. 3, p. 293-316, Set. 1993.

FARIAS, E. S. DE. Transitividades nos circuitos e cenários das festas espetáculos populares. Latitude, v. 10, n. 1, Set. 2016.

FERREIRA, M. C. Permeável, ma non troppo: a mobilidade social em setores de elites, Brasil-1996. Revista Brasileira de Ciências Sociais, v. 16, n. 47, p. 141-160, 2001.

GOLDTHORPE, J. H. The economic basis of social class. London: London School of Economics and Political Science, 2004.

GRUSKY, D. B.; SØRENSEN, J. B. Can class analysis be salvaged? American Journal of Sociology, v. 103, n. 5, p. 1187-1234, Mar. 1998.

HOUT, M.; BROOKS, C.; MANZA, J. The persistent of classes in post-industrial societies. International Sociology, v. 8, n. 3, p. 259-277, Set. 1993.

OLIVEIRA, C.; TURGEON, M. Ideologia e comportamento político no eleitorado brasileiro. Opinião Pública, v. 21, n. 3, 2015.

RENNÓ, L.; TURGEON, M. A Psicologia política das classes sociais no brasil: atributos das atitudes políticas por estratificação e mobilidade social. Dados - Revista de Ciências Sociais, v. 59, n. 1, p. 11-52, Mar. 2016.

REHBEIN, B. Classes and milieus in contemporary Brazil. Washington; Brasília: BID Report; Ipea, 2016. 
RIBEIRO, C. A. C. Class, race, and social mobility in Brazil. Dados - Revista de Ciências Sociais, v. 49, n. 4, p. 833-873, 2006.

SANTOS, J. A. F. Efeitos de classe na desigualdade racial no Brasil. Dados - Revista de Ciências Sociais, v. 48, n. 1, 2005a.

Uma classificação socioeconômica para o Brasil. Revista Brasileira de Ciências Sociais, v. 20, n. 58, p. 27-45, 2005b.

SCALON, M. C. Mapeando estratos: critérios para escolha de uma classificação. Dados - Revista de Ciências Sociais, v. 41, n. 2, p. 337-375, 1998.

SOUZA, J. A Ralé brasileira: quem é e como vive. Belo Horizonte: Editora UFMG, 2009.

WEBER, M. Ensaios de sociologia. Rio de Janeiro: Editora LTC, 1982.

WRIGHT, E. O. Understanding class: towards an integrated analytical approach. New Left Review, v. 60, p. 101-116, Nov./Dec. 2009.

- Approaches to class analysis. Cambridge (UK): Cambridge University Press, 2005 
ANEXO 1

CLASSES SOCIAIS E SUAS PONTUAÇÕES MÉDIAS

NA ESCALA DE ORIGEM SOCIAL

\begin{tabular}{|c|c|c|}
\hline Classe social & Frequência & origem \\
\hline Conta própria & 5 & 2.13 \\
\hline Conta própria precário & 58 & 1.69 \\
\hline Empregados domésticos & 3 & 1.67 \\
\hline Empregados especialistas & 80 & 3.13 \\
\hline Especialistas autoempregados & 26 & 3.27 \\
\hline Gerentes & 11 & 3.17 \\
\hline Grandes empregadores & 14 & 3.05 \\
\hline Inativo & 14 & 1.33 \\
\hline Pequenos empregadores & 17 & 2.98 \\
\hline Supervisores & 5 & 2.33 \\
\hline Trabalhadores & 54 & 2.23 \\
\hline Trabalhadores elementares & 17 & 1.93 \\
\hline Total & 304 & 2.50 \\
\hline
\end{tabular}


ANEXO 2

RESULTADOS PARA TODAS AS DIMENSÕES

DA ANÁlise de COMPONENTES PRINCIPAIS (ACP)

\begin{tabular}{|c|c|c|c|c|c|c|c|c|c|}
\hline Atitude & Cop1 & Cop2 & Cop3 & Cop4 & Cop5 & Cop6 & Cop7 & Cop8 & Cop9 \\
\hline Insegurança (-) ou autoconfiança (+) & 0.36 & 0.05 & 0.06 & 0.04 & 0.02 & 0.02 & -0.03 & -0.13 & -0.15 \\
\hline Coletivismo (-) ou individualismo (+) & -0.11 & 0.03 & 0.51 & -0.37 & 0.39 & 0.06 & 0.38 & -0.17 & -0.23 \\
\hline Heteronomia (-) ou autonomia (+) & 0.35 & 0.06 & 0.11 & 0.17 & 0.18 & -0.07 & -0.15 & -0.26 & 0.07 \\
\hline Pessimismo (-) ou otimismo (+) & 0.32 & 0.09 & -0.05 & 0.12 & 0.00 & 0.30 & 0.50 & 0.14 & 0.08 \\
\hline Passividade (-) ou atividade $(+)$ & 0.36 & 0.00 & 0.04 & 0.20 & 0.16 & -0.02 & -0.16 & -0.23 & -0.09 \\
\hline Ascetismo (-) ou hedonismo (+) & -0.02 & 0.40 & -0.01 & 0.45 & 0.10 & 0.28 & -0.27 & -0.05 & -0.41 \\
\hline Idealismo (-) ou pragmatismo (+) & 0.08 & -0.25 & 0.14 & 0.42 & 0.36 & -0.52 & 0.19 & 0.42 & -0.17 \\
\hline Atividade intelectual (-) ou física (+) & -0.25 & -0.19 & -0.13 & 0.40 & 0.23 & 0.11 & 0.32 & -0.35 & 0.24 \\
\hline Experimentalismo (-) ou tradicionalismo (+) & -0.01 & -0.46 & -0.05 & -0.11 & 0.28 & 0.18 & -0.27 & 0.23 & -0.04 \\
\hline Orientação a família (-) ou a si mesmo (+) & -0.03 & 0.31 & 0.38 & -0.05 & 0.39 & 0.19 & -0.33 & 0.28 & 0.51 \\
\hline Insatisfação (-) ou satisfação (+) & 0.31 & 0.05 & 0.07 & 0.05 & -0.17 & 0.42 & 0.32 & 0.37 & 0.06 \\
\hline Orientação a objetivos (-) ou dispersão (+) & -0.34 & 0.05 & -0.09 & 0.24 & 0.09 & 0.10 & 0.09 & -0.06 & 0.34 \\
\hline Indisciplina (-) ou disciplina (+) & 0.34 & -0.18 & -0.01 & -0.17 & -0.08 & -0.15 & -0.07 & 0.03 & 0.21 \\
\hline Fraco $(-)$ ou forte $(+)$ ethos do trabalho & 0.30 & -0.26 & -0.16 & 0.01 & 0.11 & 0.06 & -0.07 & -0.26 & 0.36 \\
\hline Meritocracia (-) ou igualitarismo (+) & 0.03 & 0.36 & -0.47 & -0.04 & 0.14 & -0.25 & 0.04 & 0.34 & 0.13 \\
\hline A favor (-) ou contra (+) intervenção estatal & -0.03 & 0.03 & 0.52 & 0.31 & -0.51 & -0.25 & -0.02 & 0.02 & 0.25 \\
\hline Autoritarismo (-) ou liberalismo (+) & 0.12 & 0.43 & -0.06 & -0.20 & 0.14 & -0.37 & 0.21 & -0.25 & 0.13 \\
\hline
\end{tabular}

\begin{tabular}{|c|c|c|c|c|c|c|c|c|}
\hline Atitude & Cop10 & Cop11 & Cop12 & Cop13 & Cop14 & Cop15 & Cop16 & Cop17 \\
\hline Insegurança (-) ou autoconfiança (+) & 0.27 & -0.31 & -0.19 & 0.17 & 0.61 & 0.36 & 0.29 & -0.05 \\
\hline Coletivismo (-) ou individualismo (+) & 0.10 & 0.05 & 0.24 & 0.29 & -0.19 & 0.18 & 0.01 & 0.02 \\
\hline Heteronomia (-) ou autonomia (+) & 0.24 & -0.20 & -0.15 & 0.28 & -0.23 & -0.46 & -0.30 & -0.38 \\
\hline Pessimismo (-) ou otimismo (+) & 0.08 & -0.13 & 0.21 & -0.42 & 0.06 & 0.16 & -0.46 & -0.14 \\
\hline Passividade $(-)$ ou atividade $(+)$ & 0.01 & -0.21 & 0.18 & -0.24 & -0.33 & -0.02 & 0.16 & 0.67 \\
\hline Ascetismo (-) ou hedonismo (+) & -0.07 & 0.46 & 0.15 & 0.13 & 0.07 & 0.14 & -0.13 & -0.06 \\
\hline Idealismo (-) ou pragmatismo (+) & -0.18 & 0.07 & -0.20 & -0.02 & 0.00 & 0.09 & -0.01 & -0.03 \\
\hline Atividade intelectual (-) ou física (+) & -0.08 & 0.01 & 0.31 & 0.06 & 0.31 & -0.31 & 0.27 & -0.02 \\
\hline Experimentalismo (-) ou tradicionalismo $(+)$ & 0.61 & 0.30 & 0.12 & -0.20 & 0.10 & -0.10 & 0.00 & 0.01 \\
\hline Orientação a família (-) ou a si mesmo (+) & -0.22 & -0.13 & 0.01 & -0.15 & 0.16 & -0.02 & 0.08 & -0.03 \\
\hline Insatisfação (-) ou satisfação (+) & 0.02 & 0.23 & -0.26 & 0.28 & -0.14 & -0.28 & 0.37 & 0.15 \\
\hline Orientação a objetivos (-) ou dispersão (+) & 0.31 & -0.03 & -0.40 & 0.26 & -0.09 & 0.30 & -0.32 & 0.38 \\
\hline Indisciplina (-) ou disciplina (+) & -0.23 & 0.25 & 0.27 & 0.40 & 0.35 & -0.05 & -0.41 & 0.33 \\
\hline Fraco (-) ou forte $(+)$ ethos do trabalho & -0.17 & 0.30 & -0.03 & 0.02 & -0.31 & 0.49 & 0.20 & -0.31 \\
\hline Meritocracia (-) ou igualitarismo (+) & 0.25 & -0.14 & 0.43 & 0.28 & -0.16 & 0.09 & 0.18 & -0.06 \\
\hline A favor (-) ou contra (+) intervenção estatal & 0.33 & 0.13 & 0.29 & -0.04 & -0.06 & 0.10 & 0.10 & -0.06 \\
\hline Autoritarismo (-) ou liberalismo (+) & 0.18 & 0.48 & -0.24 & -0.32 & 0.16 & -0.16 & 0.07 & 0.09 \\
\hline
\end{tabular}


